\title{
REFLEXÕES SOBRE A TIPOLOGIA DA INTERPRETAÇÃO DE LÍNGUAS DE SINAIS
}

\author{
Maria Cristina Pires Pereira* \\ Universidade Federal de Santa Catarina
}

\begin{abstract}
Resumo: Este texto parte de uma revisão bibliográfica com o objetivo de refletir sobre a tipologia aplicada, atualmente, à interpretação de língua de sinais. Ainda não chegamos a um consenso nem sobre os termos tradução e interpretação e somente a utilização de determinada terminologia, sem a consideração de outras possibilidades mais abrangentes de conceituação, não consegue alcançar a precisão que temos que perseguir para que consigamos intercâmbios de pesquisa que consigam dialogar.
\end{abstract}

Palavras-chave: Estudos da Tradução. Estudos da Interpretação. Interpretação de Língua de Sinais. Tipologia. Terminologia.

\section{REFLECTIONS ON SIGN LANGUAGE INTERPRETING TYPOLOGY}

\begin{abstract}
This paper is a literature review that intend to think about the typology applied currently to sign language interpretating. We did not reach a consensus on the terms translation or interpretation and only the use of certain terminology, even without consideration of other broader possibilities of conceptualization, can not achieve the precision we have to pursue so that we can exchange researching in order to promote the dialogue among researchers.
\end{abstract}

Keywords: Translation Studies. Interpreting Studies. Sign Language Interpreting. Typology. Terminology.

\footnotetext{
* Doutora em Estudos da Tradução (UFSC), mestra em Linguística Aplicada (Unisinos) e, atualmente, pesquisadora independente. Santa Catarina, Florianópolis. Brasil. Email: pirespereiramc@gmail.com
} 
A definição e distinção entre tradução e interpretação sempre me fascinaram e, no levantamento de fontes que solucionassem minhas questões, percebi que o debate não é novo, e é persistente, inclusive no campo de estudo da tradução de línguas orais. Com o reconhecimento das línguas de sinais em franco progresso mundial, as investigações sobre esta modalidade de tradução muitas vezes ignoram que “(...) em qualquer trabalho científico voltado para questões de tradução, é recomendável proceder preliminarmente a uma delimitação mais precisa daquilo que se entende por tradução" (KADE, 1968 apud CARDOZO, 2009, p. XV).

As delimitações de conceituação de atuação, entre tradutores e intérpretes, levando em conta somente textos escritos e falados e sua relação com o tempo levado no processo tradutório foram úteis, nos primórdios, quando as interações eram somente faladas, presenciais e sincrônicas ou escritas, não presenciais e assincrônicas. A atualidade nos brinda com uma diversidade inovadora nos modos de interação e, consequentemente, de mediação interlíngue.

Por meio de uma rigorosa revisão bibliográfica, apresento um convite a repensarmos sobre a necessidade não só de definirmos e declararmos explicitamente nossos termos relacionados à interpretação interlíngue ao empreendermos nossas investigações e divulgações de pesquisas.

\section{A sempre presente questão de terminologia}

Tratar sobre a interpretação e sobre os intérpretes, primeiramente, é um trabalho de definição. A polissemia do termo é extremamente variada, pois podemos nos referir à interpretação em seus aspectos: musical, cênico e dramático (teatral, televisivo, cinematográfico), jurídico, religioso, textual, médico (sintomas, exames), dentre outros. Portanto, utilizo intérprete interlíngue/interpretação interlíngue para marcar a pessoa e o fenômeno do bilinguismo que trata da mediação de interações faladas entre pessoas que não têm ou não se sentem com proficiência suficiente na outra língua, em 
contraste apenas com intérprete/interpretação, significando a compreensão subjetiva e consequente reação a um enunciado, ideia ou manifestação cultural. Também convenciono que o termo tradução, utilizado sozinho, reporta o sentido mais amplo dos intercâmbios linguísticos, abrangendo tanto a tradução escrita quanto a interpretação interlíngue.

Alguns pesquisadores da área tentaram definir a interpretação interlíngue de uma forma abrangente. Uma das mais conhecidas e veiculadas, atualmente, é: "uma forma de tradução na qual a apresentação inicial e final no outro idioma é produzida na base da apresentação única de um enunciado do idioma de partida" (POCHHÄCKER, 2004, p. 11) ${ }^{1}$, agregada ao fator tempo, por Luciano (2005), que a define "como sendo a realização, sob imposição externa da velocidade, da versão final de um texto na primeira produção feita pelo intérprete" (LUCIANO, 2005, p. 38). Gile (2004), por sua vez, simplifica a definição ao extremo, afirmando que utiliza "interpretação para uma re-expressão não-escrita de um texto fonte não-escrito" (GILE, 2004, p.11). ${ }^{2}$

Penso que seria imprescindível, neste momento no qual os Estudos da Interpretação estão em franca expansão, um debate maior em busca de bases delimitantes. Se analisarmos que a interpretação interlíngue surgiu em tempos remotos, sem tecnologias que permitissem outras formas de mediação entre línguas que não fosse a presencial, na qual os interlocutores estivessem face a face em um espaço físico que permitisse uma interação síncrona entre eles, não é de estranhar que houvesse somente a concepção de interpretação de e para uma língua falada, e tradução de e para uma língua escrita. Com a evolução dos meios de comunicação, as modalidades híbridas entre traduções escritas e interpretações faladas compõem um desafio terminológico e conceitual.

Nos dias atuais, com a popularização das comunicações tecnológicas, presenciais e a distância, sincrônicas e assíncronas, as formas de interação, consequentemente, também se diversificaram. Não existe mais, somente, comunicação falada e escrita, podemos gravar nossas vozes e movimentos corporais, conversar, 
dar aula e conferências a distância, com ou sem nossa imagem corporal (BRAUN, 2006). Mesmo sem considerarmos os avanços tecnológicos, o fenômeno antigo, no qual um intérprete parte de um texto escrito e o entrega diretamente para a língua falada, pode ser referido como tradução oral à [prima] vista (SAMPAIO, 2007; IVARS, 1999), tradução à [prima] vista executada por um intérprete (NAJIT, 2006; BIDAR-SIELAFF et al., 2009), ou, mais apropriadamente, interpretação à [prima] vista (sight interpreting) (PÖCHHACKER, 2004; GORSZCZYNSKA, 2010).

A discussão é fértil e, com o rápido desenvolvimento de modos de estarmos e nos manifestarmos no tempo e no espaço, urge uma revisão das maneiras possíveis de tradução e/ou interpretação. Apenas para citarmos alguns exemplos, dentre outras possibilidades cada vez mais diversificadas de procedermos a uma interação mediada por intérprete interlíngue, temos:

- interpretação remota e de teleconferências (FURTADO; ALMEIDA; PASCOAL, 2009) que permitem interações com possibilidade de gravação, preparação e interpretação posterior;

- utilização de avatares e robôs como demonstrado no recente congresso Tahir International Symposium on Sign Language Translation and Avatar Technology ${ }^{3}$;

- mensagens de voz, por correio eletrônico, que, apesar de utilizarem um modo similar à conversação simultânea, podem ser recebidas e interpretadas em uma condição não síncrona;

- a tradução audiovisual, em geral, e especificamente a legendagem (língua oral para língua escrita) e, a dublagem, que constitui um processo complexo de traduzir uma língua oral para a escrita e será veiculada, em língua oral, por um dublador profissional ou algum ator/atriz ${ }^{4}$.

Em 2008, a partir de reflexões do meu mestrado, fiz uma tentativa de definição baseada no que utilizamos para sua detecção: a língua meta. O processo da tradução ou interpretação é considerado em termos de pesquisa, porém, quando há a necessidade 
de caracterizar uma atividade como tradução ou interpretação, o fenômeno observado é o produto. Portanto, considero que "se a língua meta estiver na modalidade escrita, trata-se de uma tradução; se estiver na modalidade vocal (também chamada de oral) ou sinalizada (presenciais ou de interação imediata), o termo utilizado é interpretação" (PEREIRA, 2008a, p. 136).

Mesmo não querendo adentrar muito na questão da diferenciação entre a tradução e a interpretação, para que se possa entender a conceituação que faço da interpretação interlíngue é necessário entender como concebo estas duas principais divisões da tradução. Para tanto, esquematizei no quadro 1, as etapas em que percebo diferenças, vejamos:

\begin{tabular}{|l|l|l|}
\hline Etapas & Tradução escrita & $\begin{array}{l}\text { Interpretação } \\
\text { interlíngue }\end{array}$ \\
\hline Produção & $\begin{array}{l}\text { Escrever à mão, } \\
\text { datilografar, digitar. }\end{array}$ & $\begin{array}{l}\text { Falar por meio de } \\
\text { vocalização ou por } \\
\text { sinalização. }\end{array}$ \\
\hline Apresentação & Escrita. & Movimentos corporais. \\
\hline Registro & $\begin{array}{l}\text { Escrita: textos físicos ou } \\
\text { eletrônicos. }\end{array}$ & $\begin{array}{l}\text { Nenhum: os movimentos } \\
\text { corporais não deixam } \\
\text { traços. }\end{array}$ \\
\hline Armazenamento & Automático. & Não automático. \\
\hline
\end{tabular}

Quadro 1: A tradução e a interpretação interlíngue quanto à produção, apresentação, registro e armazenamento

Tanto a tradução quanto a interpretação interlíngue são produzidas com movimentos corporais. A diferença é que escrever é um movimento mais discreto, banalizado e estamos tão acostumados com ele que não o percebemos mais. O escrever vem evoluindo paralelamente a nossa tecnologia, mas ainda depende, basicamente, 
de uma interação direta com os instrumentos para produzir a escrita (lápis, caneta, teclado etc.). A interpretação interlíngue quando é produzida com a voz (línguas orais) é, também, constituída de movimentos corporais discretos dos órgãos fonoarticulatórios, sendo que boa parte deles se produz internamente (pregas vocais) ou em partes do corpo que não apresentam muita amplitude (músculos, ossos e tendões da face). Já a interpretação para uma língua de sinais produz movimentos bastante amplos, principalmente dos membros superiores e, por esta característica, é bastante visível na sua articulação.

A apresentação da escrita é a própria escrita, enquanto escrevemos a escrita vai sendo construída e fixada. A escrita, como processo, resulta na escrita como produto. $\mathrm{O}$ ato de escrever produz a escrita. O produto final é estático, fica fixo e marcado no texto. A escrita é um produto da fala (exterior ou internalizada), por ser sua derivada e criada para registrá-la.

A apresentação da interpretação é o corpo em movimento, inerente da dinâmica da língua falada. A fala não resulta em um produto material em si. Como a escrita foi concebida para ser um produto, o seu armazenamento acontece automaticamente, em meio físico ou eletrônico. No caso da interpretação interlíngue, o armazenamento se constituiu em um desafio até bem pouco tempo, mas, mesmo assim, para termos um material para consultá-la temos que utilizar ferramentas de gravação externas aos atos de mediação linguística para este propósito.

Enquanto, na tradução, o ato de traduzir produz intrinsecamente a escrita, na interpretação interlíngue temos que lançar mão de outras tecnologias para armazenarmos a fala (oral ou sinalizada).

Tendo em vista tudo o que foi exposto, elaborei uma definição de interpretação interlíngue, que pode ser aplicada a qualquer modalidade (oral, sinalizada, tátil):

A interpretação interlíngue é um fenômeno da tradução geral (língua $A \leftrightarrow$ língua $B)$, apresentado, em língua meta, na língua falada (oral, sinalizada ou tátil ${ }^{5}$ ), com ou sem possibilidade de preparação e ensaio, no qual o corpo do intérprete é, além de meio de produção, a apresentação do produto. 
Se os diversos modos de manifestação e veiculação da língua(gem) tornam complexa a tarefa de distinção dentro da grande área dos Estudos da Tradução, a categorização interna dentro dos Estudos da Interpretação vai muito além do que a mera identificação da interpretação de conferências, como veremos.

\section{Fatores que determinam as diferentes tipologias}

A interpretação interlíngue é exercida por pessoas que colocam suas habilidades bilíngues a serviço da mediação entre pessoas que não compartilham a mesma proficiência nas línguas da interação, podendo receber ou não remuneração para este fim. Um processo de categorização dos tipos possíveis de interpretação depende da variável que é escolhida para tal e, em alguns casos, não há um limite definido entre uma e outra atuação. Grbić e Pöllabauer (2006) chamam a atenção sobre os termos, pouco consistentes e ambíguos, que utilizamos para categorizar a interpretação, tais como tipo, modo/modalidade, contexto (setting), dentre outros. Vários autores se utilizam destas e de outras palavras (prática, forma, manifestação etc.) para delimitarem e categorizarem dentro dos Estudos da Interpretação e, por isso, faço uso de "tipologia" como termo geral que abrange diversas categorias: modalidade na qual as línguas são articuladas, tempo de entrega na língua meta, formação e profissionalização, atuação intra ou intersocial e aspecto mono ou dialógico.

\section{Modalidade}

A distinção primordial e que, inclusive, serve como diferenciação entre as formas de traduzir (escrita) e interpretar (fala) é feita pela modalidade das línguas envolvidas. De uma forma esquemática, elaborei um quadro que relaciona as modalidades da língua, sua direcionalidade e a denominação da forma de tradução resultante. 


\begin{tabular}{|l|l|l|l|}
\hline LÍNGUA FONTE & Direção & LÍNGUA META & Nomeação \\
\hline Oral & $\rightarrow$ & Oral & $\begin{array}{l}\text { Interpretação } \\
\text { oral }\end{array}$ \\
\hline Escrita de língua oral & $\rightarrow$ & Oral & $\begin{array}{l}\text { Tradução/ } \\
\text { interpretação } \\
\text { oral à vista }\end{array}$ \\
\hline Sinalizada & $\rightarrow$ & Oral & $\begin{array}{l}\text { Interpretação } \\
\text { de língua } \\
\text { de sinais } \\
\text { (vocalização) }\end{array}$ \\
\hline Oral & $\rightarrow$ & Escrita de língua oral & $\begin{array}{l}\text { Transcrição- } \\
\text { tradução? }\end{array}$ \\
\hline Oral & $\rightarrow$ & Sinalizada & $\begin{array}{l}\text { Interpretação } \\
\text { de língua } \\
\text { de sinais } \\
\text { (sinalização) }\end{array}$ \\
\hline Escrita de língua oral & $\rightarrow$ & Escrita de língua oral & $\begin{array}{l}\text { Tradução } \\
\text { (escrita) }\end{array}$ \\
\hline Escrita de língua oral & $\rightarrow$ & Sinalizada & $\begin{array}{l}\text { interpretação } \\
\text { à vista }\end{array}$ \\
\hline Sinalizada & $\rightarrow$ & Escrita de língua oral & $\begin{array}{l}\text { Transcrição- } \\
\text { traduça?o }\end{array}$ \\
\hline Sinalizada & $\rightarrow$ & Sinalizada & $\begin{array}{l}\text { Interpretação } \\
\text { de língua de } \\
\text { sinais }\end{array}$ \\
\hline
\end{tabular}

Quadro 2: Nomeação das formas de tradução segundo as modalidades envolvidas

Nos casos em que o resultado é uma transcrição-tradução, praticamente inexistem estudos disponíveis, na perspectiva dos Estudos da Tradução ou Interpretação, sobre esta forma de tradução que, se nas línguas orais não é usual, a não ser na tomada de notas que os intérpretes de línguas orais fazem. Nas línguas de sinais é comum e extensa quando, por exemplo, uma pessoa sinaliza, em Libras, e pede ao intérprete de língua de sinais (ILS) para es- 
crever diretamente em Português Brasileiro (PB). É uma espécie de tradução à prima vista ao contrário, e que não possui uma denominação única e padronizada. Este tema demanda estudos adicionais e, não fazendo parte do escopo deste trabalho mergulhar nos aspectos de diferenciação entre tradução e interpretação, fica registrado como uma possibilidade futura de desenvolvimento. Deve ser observado que detalhei "escrita de língua oral" em oposição às tentativas de desenvolvimento de uma escrita de língua de sinais (PEREIRA; FRONZA, 2006) e não incluí as línguas de sinais táteis nesta categorização, exatamente por exigir um estudo mais aprofundado destas modalidades para poder chegar a um resultado mais amplo.

\section{Tempo}

Em muitas obras bibliográficas sobre a interpretação interlíngue, a divisão mais comum entre as variedades de atuações consiste na interpretação consecutiva e na simultânea. Como vários trabalhos são derivados desta classificação, não me deterei em extensos detalhamentos devido à existência de vasta bibliografia sobre este tema e por ser um conhecimento básico neste campo disciplinar. Esta divisão é feita com base no fator tempo, mais especificamente no tempo levado entre a enunciação na língua fonte e sua interpretação na língua meta e na sobreposição, ou não, das falas do locutor primário e dos intérpretes interlíngues.

Na maioria dos casos, a interpretação simultânea, para ser bemsucedida, tem que garantir que a produção das línguas envolvidas não prejudique a sua recepção. Tal garantia pode se dar pela utilização de cabinas na interpretação interlíngue de línguas orais e na diferença de modalidade entre a língua de sinais e a oral. Uma categoria híbrida seria o voice-over, muito comum em transmissões televisivas nas quais o locutor fala em um idioma, com áudio mais baixo, e, logo em seguida, é interpretado, na língua meta, com o volume do áudio mais alto, como no exemplo típico da cerimônia 
de entrega do Oscar. Outra categoria é a interpretação oral sussurrada que, por sua natureza, na qual duas modalidades orais competem, é entregue na forma consecutiva curta, seguindo o locutor primário com algumas frases de atraso, ou longa, quando é esperado que se termine um período mais longo de fala, preferencialmente contendo uma ideia fechada, para só então começar a interpretar.

\section{Formação e profissionalização}

A mais precoce forma de mediação interlíngue é a tradução natural, definida como "a tradução feita em circunstâncias do dia a dia por bilíngues que não têm nenhuma formação para isto" (HARRIS, 1977, p. 99) ${ }^{6}$, tida como uma competência intuitiva inerente ao bilinguismo. Para (2008), a pesquisa sobre a tradução natural tem se concentrado em crianças e adolescentes, mas tradutores naturais podem ser encontrados em qualquer faixa etária. Harris e Sherwood (1978) compilam uma série de exemplos de tradução natural em crianças, para embasar seu pressuposto de que a tradução é uma competência inata, postulando que todos os bilíngues podem traduzir, ao que eu complemento: porém não nas condições exigidas na tradução profissional. A tradução natural, portanto, é feita sem nenhum processo educativo formal ou informal, feita por, praticamente, qualquer criança e adolescente em um ambiente de interação onde duas ou mais línguas estejam presentes. Segundo os defensores da ideia de tradução natural, não se ensina às pessoas bilíngues a traduzir, pois elas já possuem esta habilidade, "o que fazemos é treiná-las [sic] a traduzir de acordo com certas normas"7 (LJUDSKANOV, 1972 apud HARRIS, 2008, p. 12). É de importância para a área dos Estudos da Interpretação a nota na qual Fuente $(2005$, p. $61 ; 2007$, p. 85) cita que o próprio Harris (2003) admite que "o termo mais adequado para este fenômeno seria interpretação natural ${ }^{8 ”}$.

Avançando um pouco em termos de formação e preparação, temos o tradutor nativo que, apesar de não ter recebido nenhuma 
educação formal na área, adquiriu suas habilidades por meio da observação e experiência. Toury (1986), a quem é devida a cunhagem do termo, complementando o conceito de tradutor natural, frisou que a habilidade de traduzir precisa desenvolver-se, principalmente, na interação social.

Um caso de tradutores naturais e nativos que tem, recentemente, despertado muito interesse dos pesquisadores é a mediação interlinguística feita por crianças e adolescentes pertencentes a famílias e comunidades de imigrantes, refugiados ou até mesmo CODA (Children of Deaf Adults, filhos ouvintes de pais surdos), estudada sob o título de child language brokering ${ }^{9}$. A gama de situações nas quais as crianças e adolescentes são chamados a traduzir são muito amplas e vão desde trâmites burocráticos, consultas médicas e até, em alguns casos, audiências jurídicas (HALL; GUÉRY, 2010; ANTONINI, 2010).

Morales e Hanson (2005) detalham o processo de child language brokering como o que acontece, comumente, no caso de famílias estrangeiras que, ao se mudarem para um novo país, ou região de língua diversa da sua, precisam passar por um processo, no mais das vezes, estressante de adaptação ao novo ambiente, ao sistema de crenças e, de modo particular, à(s) nova(s) língua(s). Em geral, os pais, familiares, ou até a mesma comunidade imigrante tendem a utilizar-se das crianças como tradutoras e intérpretes. Elas são as primeiras a aprender o novo idioma e a ter mais contato com a nova cultura por causa da escolarização (ANTONINI, 2010). Vários autores mencionam a "adultificação" (CURTIS, 2008; ANTONINI, 2010; TRICKETT, SORANI; BIRMAN, 2010; ESQUIVEL, 2012) destes pequenos tradutores e intérpretes como preocupante, pois a utilização de pessoas muito jovens e ainda imaturas como responsáveis por questões que, normalmente, não deveriam se ocupar tão precocemente pode trazer prejuízos psicológicos. Essas crianças e adolescentes experimentam sentimentos contraditórios que vão desde o orgulho, por estarem no importante papel de mediadores linguísticos, que facilitam a integração de seus familiares, até o estresse, a frustração e a angústia causados pela imensa 
responsabilidade diante das situações interpretadas. Tais situações podem ultrapassar seus conhecimentos e feri-los emocionalmente, quando ocorrem preconceito e discriminação, uma vez que, geralmente, não possuem maturidade, equilíbrio e distanciamento para interpretarem (ANTONINI, 2010).

Outra possibilidade de interpretação interlíngue não profissional é o caso do intérprete ad hoc (MIKKELSON, 2004; RUSSO, 2004; QUEIROZ, 2011; MEYER, 2012). Nessa situação, a pessoa bilíngue ou que se autodeclara bilíngue é chamada ou se dispõe a interpretar. Em geral, a interpretação ad hoc é voluntária e percebida como um "tipo de obrigação social ou moral” (BICOM, 2013, $\mathrm{s} / \mathrm{p}$ ). O intérprete ad hoc pode pertencer a qualquer faixa etária, englobando, em alguns casos, o processo de child language brokering, mas pessoas não envolvidas por laços familiares, étnicos ou comunitários podem também mediar a interação, como pressupõe a categorização feita por Queiroz (2011, p. 52):
a. funcionários bilíngues;
b. amigos e familiares do paciente;
c. intérpretes voluntários sem treinamento e intérpretes contra- tados (freelancer, por exemplo), como os chamados medical concierge, que não possuem treinamento específico.

Infelizmente, a interpretação ad hoc, por si só, deveria ser uma exceção, por seus aspectos, predominantemente, amadorísticos. Em muitos casos, por praticidade, emergência ou economia, tornou-se a regra, mesmo com a demonstração de várias pesquisas sobre a superioridade qualitativa da interpretação feita por profissionais (JACOBS et al., 2001; FLORES et al., 2003; FLORES, 2005; KARLINER et al., 2007; NÁPOLES et al., 2010).

Os ILS foram comumente chamados de intérpretes naturais ou, principalmente, empíricos (PEREIRA, 2008a, p. 38) desde o Programa de Formación de Formadores de Intérpretes de Sordos, organizado pela Federação Mundial dos Surdos (FMS) e pela UNESCO, em 2001, no Uruguai (MACHADO; FAMULARO, 2001). 
As pessoas que desempenham a interpretação de língua de sinais, sem formação profissional, deveriam ser chamadas, mais apropriadamente, de intérpretes ad hoc.

Embora não façam parte de seu espectro de pesquisa, Harris (2010) cita, ainda, a figura do tradutor profissional como a pessoa que exerce a tradução como um meio de vida e que pode não ter tido estudo formal, e o tradutor experto, ou tradutor formado, como o indivíduo que passou por algum tipo de educação na área de tradução, seja ela formal (ensino técnico, tecnológico ou universitário, cursos de extensão etc.) ou informal (cursos livres).

\section{Atuação social}

É possível optarmos pelo contexto social amplo de interação (PÖCHHACKER, 2004) como um item distintivo e, assim, teremos situações de atuação inter e intra sociais.

$\mathrm{Na}$ atuação Intrassocial, temos, por exemplo, um intérprete comunitário que atua dentro de uma comunidade, geralmente minoritária, vivendo em um contexto amplo de outra comunidade majoritária. Tem sido chamada, também, de interpretação cultural, interpretação de serviços públicos, interpretação de diálogos e interpretação ad hoc, porém o termo mais utilizado e aceito é interpretação comunitária (MIKKELSON, 2004). Esta indistinção entre a interpretação comunitária e ad hoc, a meu ver, relaciona-se à possibilidade de os intérpretes comunitários não terem formação e prestarem serviços, muitas vezes, voluntários. Isso, porém, não exclui o fato de que existam profissionais freelancers (QUEIROZ, 2011), quer dizer, os intérpretes ad hoc seriam uma categoria dentro da interpretação comunitária. A proliferação terminológica é tão grande quando não se trata de intérpretes de conferências que, até mesmo, outros termos foram cunhados, tais como mediação intercultural, interpretação de acompanhamento, ou de contato, dentre outros (RUSSO, 2004). 
A interpretação comunitária é uma das áreas de mais difícil delimitação da interpretação interlíngue e tem obtido muita visibilidade nos últimos anos. Os movimentos migratórios, o empoderamento de minorias e a conquista de direitos em legislação vêm aumentando o espectro de atuação e, de certa forma, prestigiando o intérprete comunitário. Como exemplos, posso citar os hispanofalantes nos Estados Unidos e as pessoas surdas, falantes de línguas de sinais, nas sociedades falantes de línguas orais.

Situações de atuação em contexto intersocial, por sua vez, são realizadas em meio a diversas comunidades falantes de línguas diferentes, principalmente em uma convivência entre estrangeiros, que é a situação mais conhecida de interpretação interlíngue. Se pensarmos em uma ocorrência prototípica de interpretação comunitária entre um imigrante, um intérprete interlíngue e um médico teremos, na interação paciente-intérprete, a caracterização Intrassocial. Porém, na relação médico-intérprete, compreendemos a definição de uma interpretação intersocial.

Desta maneira, concluo que, em geral, uma interpretação em situação intersocial acontece mais frequentemente em encontros internacionais acadêmicos, políticos e religiosos, em eventos de curta duração.

Schjoldager (1997), conforme o Quadro 3, sistematiza itens que contribuem para a distinção entre interpretação comunitária e não comunitária.

\begin{tabular}{|l|l|}
\hline \multicolumn{2}{|l|}{ INTERPRETAÇÃO INTERLÍNGUE } \\
\hline COMUNITÁRIA & NÃO COMUNITÁRIA \\
\hline $\begin{array}{l}\text { Um interlocutor sempre representa } \\
\text { a cultura majoritária, e outro, a } \\
\text { minoritária. }\end{array}$ & $\begin{array}{l}\text { Pode haver dificuldade em } \\
\text { detectar quem representa a } \\
\text { cultura majoritária. }\end{array}$ \\
\hline $\begin{array}{l}\text { O membro da cultura majoritária está } \\
\text { em uma condição social de poder. }\end{array}$ & $\begin{array}{l}\text { Os interlocutores } \\
\text { frequentemente encontram-se } \\
\text { em condições mais ou menos } \\
\text { igualitárias de poder. }\end{array}$ \\
\hline
\end{tabular}




\begin{tabular}{|l|l|}
\hline \multicolumn{2}{|l|}{ INTERPRETAÇÃO INTERLÍNGUE } \\
\hline COMUNITÁRIA & NÃO COMUNITÁRIA \\
\hline $\begin{array}{l}\text { O membro da cultura majoritária, } \\
\text { frequentemente, possui algum estatuto } \\
\text { social, provendo algum tipo de } \\
\text { serviço (juiz, médico, assistente social } \\
\text { etc.), enquanto o membro da cultura } \\
\text { minoritária atua em seu próprio } \\
\text { interesse (réu, paciente, refugiado } \\
\text { etc.). }\end{array}$ & $\begin{array}{l}\text { Os interlocutores, } \\
\text { frequentemente, compartilham } \\
\text { cultural bem próximos. }\end{array}$ \\
\hline $\begin{array}{l}\text { O membro da cultura majoritária tende } \\
\text { a falar em uma linguagem profissional } \\
\text { mais formal, enquanto o membro da } \\
\text { cultura minoritária tende a falar uma } \\
\text { linguagem mais informal, do dia a dia. }\end{array}$ & $\begin{array}{l}\text { O nível linguístico que os } \\
\text { interlocutores utilizam, no } \\
\text { momento da interação, tende } \\
\text { a ser equivalente. }\end{array}$ \\
\hline
\end{tabular}

Quadro 3: Distinção entre interpretação comunitária e não-comunitária, segundo Schjoldager (1997)

Tanto os intérpretes comunitários quanto os de conferência podem especializar-se em um determinado campo do conhecimento e, então, teremos a interpretação especializada: médica, jurídica e educacional, principalmente. Nada impede que um intérprete interlíngue comunitário atue como intérprete de conferências. Este é um caso bastante comum entre os ILS, pois, devido a sua escassez e relativa baixa remuneração (tendo em vista a complexidade e amplitude dos serviços prestados) não conseguiriam se manter em atividade na qual atuassem com públicos muito específicos. Exceção feita aos intérpretes educacionais, esta subárea é a que mais empregos formais oportuniza para os ILS.

Nesta pesquisa, estou usando materiais de interpretação que podem, também, ser caracterizados como do tipo comunitária, embora em alguns casos, como em uma reunião de professores em que participam docentes ouvintes e surdos, esta distinção não fique muito marcada. 
Reforçando que nenhuma das categorizações, automaticamente, elimina outra e que mais de uma tipologia pode acontecer na mesma situação de interpretação interlíngue, abordo, na sequência, a visão monológica e dialógica da mediação entre línguas.

\section{Monologismo ou dialogismo}

A concepção da interpretação dialógica ou interpretação de diálogos (WADENSJÖ, 1995, 1998, 2004; BOT, 2005) enfatiza o caráter presencial do evento e a dupla função, não só do intérprete, mas também do organizador da interação. Em uma perspectiva dialógica da interpretação interlíngue, uma só pessoa não pode controlar toda a interação, pois não consegue ter o poder absoluto sobre todas as palavras, frases, enunciações porque este é um movimento entre todos os participantes. Nesta abordagem, todos são responsáveis pelo sucesso, ou não, do ato de linguagem, e os intérpretes interlíngues devem considerar, também, outros aspectos, muito além dos puramente linguísticos na sua função. Qual a relação que os interlocutores têm entre si, como executam as suas intenções comunicativas (nível linguístico, variedade de língua, tom de voz, estilo discursivo etc.), que postura emocional e psicológica tomam ao relacionar-se entre si, dentre outros fatores, são elementos integrantes da interação e são levados em conta quando os participantes se encontram para proceder a um diálogo.

A visão monológica percebe a manifestação linguística independente dos sujeitos que a expressam, preocupa-se mais com o texto (fonte/origem, alvo/meta) do que com o contexto. É nesta perspectiva que são concebidos os erros e condutas corretas como provindos, prioritariamente, da parte do intérprete interlíngue, sem considerar o todo da interação.

$\mathrm{Na}$ perspectiva da interpretação interlíngue como um ato monológico, a ação está concentrada no intérprete e nas línguas envolvidas. Por outro lado, na abordagem dialógica, todos os envolvidos são responsáveis e coparticipantes do encontro comunicativo. En- 
tendo que, nesta concepção, há interpretação interlíngue que deve considerar todos os itens envolvidos: é sempre fala situada entre três sujeitos, contextual, construída a cada momento em que ocorre; é ação, acima de tudo.

Não existe, portanto, somente um tipo de categorização; muitas das categorias se interpenetram e são, por natureza, híbridas. Outros tipos de classificação poderiam ser pensados, dependendo do traço distintivo a se destacar, por exemplo, poderíamos ainda dividir a interpretação interlíngue em unimodal/ monomodal (entre línguas orais ou entre línguas de sinais) ou bimodal/intermodal (entre uma língua de sinais e uma língua oral (NICODEMUS; EMOREY, 2013) e assim por diante.

Nosso dever, como investigadores, e no estágio em que nos encontramos, é explicitar de qual aspecto estamos fazendo nosso recorte e análises em nossos trabalhos.

\section{Atuações híbridas? Transcrições e traduções}

Neste trabalho, analiso falas orais em PB, porém, como se trata de uma investigação sobre a interpretação interlíngue, a enunciação original parte de outra língua. Articulada em uma modalidade diferente da oral-auditiva, a Libras (e todas as línguas de sinais) vem trazendo um problema de difícil resolução para as pesquisas porque, para o processamento, análise e armazenamento de línguas de sinais, é necessária uma representação textual e gráfica.

Pesquisadores da área vêm apontando em seus trabalhos as dificuldades (ANATER, 2009) e o desafio (RODRIGUES, 2009) de transcrever uma língua de sinais. Se consideramos que a transcrição de dados oriundos de uma língua falada com o propósito de descrição, para fins de estudo de aquisição, bilinguismo etc., já é uma atividade extenuante, tanto do ponto de vista físico quando cognitivo, transcrever as falas envolvidas em uma interpretação interlíngue, entre duas línguas com sistemas alfabéticos diferen- 
ciados, ou, como no nosso caso, de modalidades diferentes, é um trabalho levado aos limites de nossas capacidades. Então,

como traduzir os dados da Libras, registrados em vídeo, em símbolos gráficos capazes de dar conta das nuanças da interpretação e, ao mesmo tempo, evidenciar o uso que os intérpretes fazem da língua [...]? (RODRIGUES, 2013, p. 105)

Em uma perspectiva mais enunciativa, podemos divisar o quão complexa é esta tarefa, pois a análise se dá considerando, na verdade, quatro enunciações.

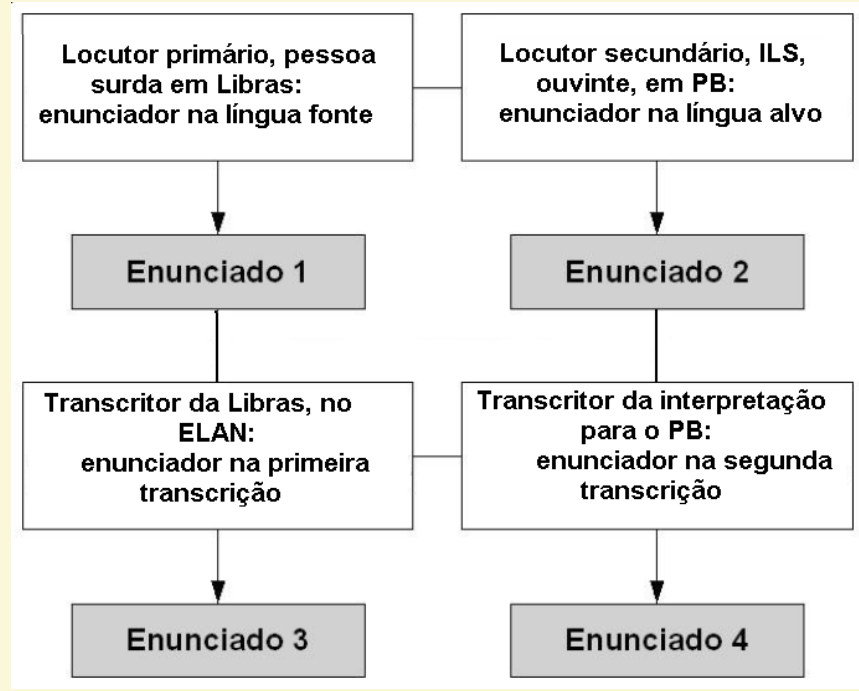

Figura 1: Esquema de quádrupla enunciação, segundo Frydrych (2010), adaptado

$\mathrm{Na}$ figura 1, utilizei o esquema de quádrupla enunciação, proposto por Frydrych (2010) que problematiza a transcrição da Libras e adaptei-o às circunstâncias específicas de minha inves- 
tigação. Assim existe a enunciação primária, em Libras e que é interpretada para o PB pela ILS, a enunciação secundária e, esta é a situação corriqueira de qualquer interpretação interlíngue. A partir daí, outras enunciações são produzidas para efeitos de pesquisa. A quarta enunciação é feita pelo transcritor da Libras para as glosas, no ELAN e, em algumas investigações, principalmente aquelas que enfocam somente a Libras, o processo acaba aqui. No entanto, em uma pesquisa que analisa a interpretação para outra língua é necessário que a língua meta também seja transcrita, o que gera a segunda transcrição e a quarta enunciação. Como bem ressalta Frydrych (2010), ocorrem duas "transposições intermodais": da Libras, visual-gestual, para o PB, oral-auditivo, e da Libras e do PB falados para a língua escrita.

As línguas orais compartilham sua origem sonora. Mesmo com sistemas de escrita diferentes, podem ser feitas tentativas razoavelmente bem-sucedidas de uma aproximação fonética. As estratégias de transcrição de línguas orais baseiam-se, de uma forma ou outra, na escrita e utilizam-se de técnicas (1) puramente alfabéticas, no próprio idioma de produção da amostra, (2) transliterações, no caso de línguas com sistemas de escrita diferentes ou (3) fonéticas. Então, como transcrever uma língua ágrafa e não baseada em sons e sim em imagens? Como "escrever" imagens?

Bergeron (2006) procedeu a uma tipologia de sistemas de escrita para línguas de sinais e colocou em relevo várias maneiras diferentes para transcrição e escrita de sinais. Estas diferenças são geradas tanto por necessidades específicas de representação (fonológica, sintaxe, escrita corrente) quanto por restrições humanas, tais como legibilidade, facilidade de aprendizado, utilização e memorização, técnicas ou de pesquisa, como ser passível de informatização eletrônica e intercâmbio de dados. Miller (1994 apud BERGERON, 2006), além de listar uma série de tentativas para o desenvolvimento de um sistema de notação de sinais (notação Stokoe, LaMont West, Papaspyrou, HamNoSys, Jouison, notação de dança Laban-Benesh, Liddell-Johnson, SignFont), adverte que "a pluralidade desses sistemas e funções particulares para as quais 
foram criados podem complicar a difusão e a acessibilidade das pesquisas de cada um [dos investigadores]" (Op. cit., p. 6)

Atualmente, a Sign Language Linguistics Society (SLLS) recomenda, dentre diversos sistemas de transcrição, os seguintes:

- ELAN.

- SignStream.

- HamNoSys.

- The Berkeley Transcription System.

- Facial Action Coding System.

- Signwriting.

No Brasil, existem esforços para estabelecer sistemas de escrita e transcrição de sinais (STUMPF, 2005; BARROS, 2008; LESSADE-OLIVEIRA, 2012), porém, assim como no cenário internacional, não há um consenso sobre uma padronização nas transcrições. Ao contrário, novas propostas surgem, talvez, por não termos chegado, ainda, a uma forma que satisfaça a maioria dos objetivos dos pesquisadores.

\begin{tabular}{|c|c|c|c|c|c|c|c|}
\hline $\begin{array}{c}\text { Configurações } \\
\text { de mão }\end{array}$ & & minúsculas & maiúsculas & $\begin{array}{c}\text { Configurações } \\
\text { de mão }\end{array}$ & & minúsculas & maiúsculas \\
\hline $\mathrm{a}$ & i & 100 & 108 & ipsilon & ๗ & $\mathrm{lm}$ tme & vir $\mathrm{m}$ f \\
\hline bê & 8 & $m r^{m}$ & III prr $^{m}$ & zê & to & h $h$ & h 9 \\
\hline bê espraiado & 5 & سب bllel & $\Perp N$ qu & cinco & H. & fr $f^{n}$ & $\mathrm{~N}$ or \\
\hline cê & 3 & 02 & 09 & seis & it & 66 & 68 \\
\hline cê espraiado & 24 & ow see & Ш山 Sw & concha & 욤 & $r p$ & $\gamma q$ \\
\hline cê encolhido & 3 & (1) 2 & (1) 2 & mão espalmada & 8 & vml fm & $\sqrt{11}$ नाre \\
\hline
\end{tabular}

Figura 2: Amostra da mais recente tentativa do estabelecimento de um Sistema de Escrita para a Libras (SEL), segundo LESSA-DE-OLIVEIRA (2012, p. 168)

Os investigadores nacionais têm experimentado diversos métodos de transcrição. O mais conhecido e utilizado, até alguns anos atrás, era o sistema de glosas, como pode ser visto na Figura 3. 


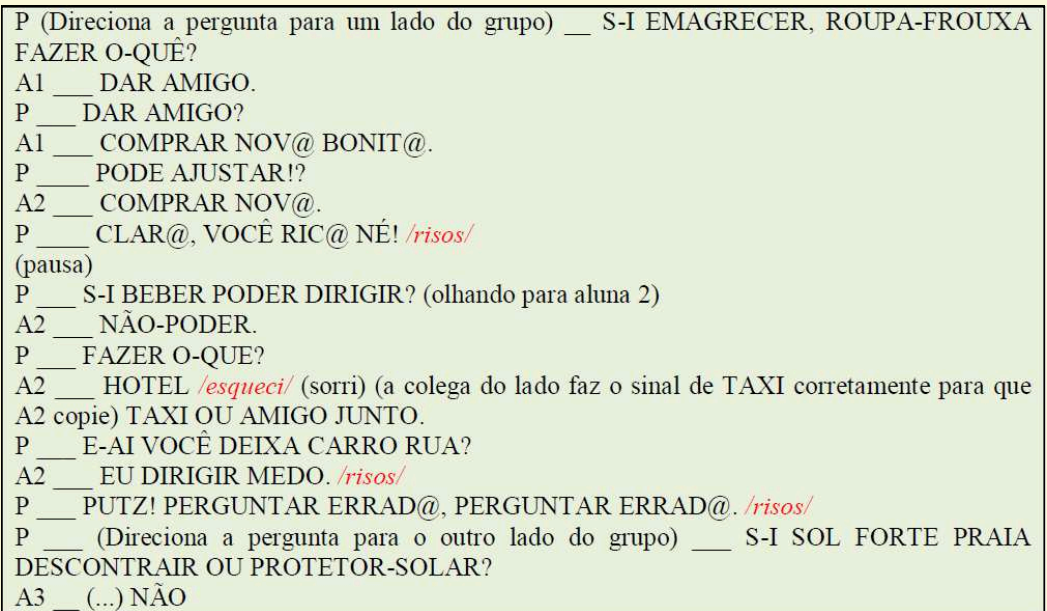

Figura 3: Exemplo de transcrição da Libras em glosas, segundo Albres (2006, p. 134)

Outro método de transcrição adotado em alguns trabalhos nacionais é o sistema Signwriting de escrita de sinais. O que percebo é que este sistema nem sempre é mantido por pesquisadores que fazem uso dele (QUADROS, 1995; RODRIGUES, 2008) talvez por sua não total aceitação nas comunidades surda e acadêmica.

$\mathrm{Na}$ leitura de várias dissertações e teses, percebi que, em geral, os autores transcrevem em glosas, inicialmente. No trabalho seguinte, alguns migram para o Signwriting e, atualmente, muitos estão se utilizando do ELAN (que não deixa de ser um sistema de glosas, porém com mais recursos). 
$1 \mathrm{P} \quad$ sw

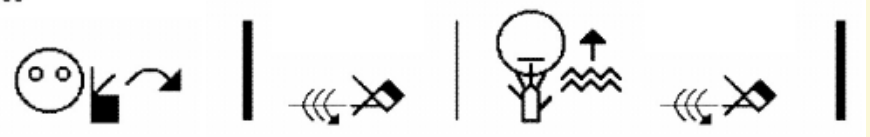

1P FB [OLHAR LÁ]

2AR sw

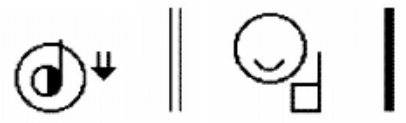

2AR fB [AMARELO ...... U U $]$

3P sw

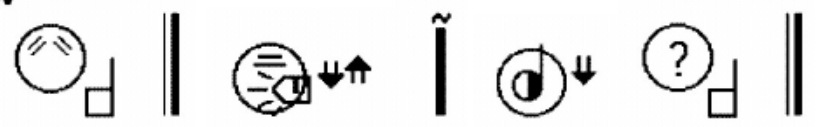

$3 P$ FB [UM] [NÃO-ENXERGAR] [AMARELO UM]

4P sw

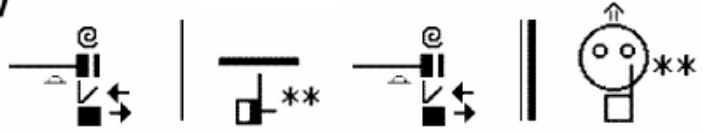

4P FB [VERDE ... TER VERDE] [VER]

Figura 4: Exemplo de transcrição da Libras, em Signwriting, segundo Rodrigues (2008, p. 213)

O que tem acontecido, ainda, é que "pesquisadores em busca de um modelo de transcrição na literatura existente, têm achado variedades de sistemas mutuamente incompatíveis" ${ }^{13}$ (DRESSLER; KREUZ, 2000, p. 26). Esta profusão de sistemas de transcrição acaba se constituindo em falta de uniformidade e, consequentemente, de poucas chances para uma apreciação, intercâmbio e cooperação entre trabalhos na área das línguas de sinais. 
Em meu doutorado, por orientação, unânime, da banca de qualificação, fui requisitada a utilizar o programa $\mathrm{ELAN}^{14}$ para transcrever as interações. Um dos maiores argumentos, a favor do ELAN, é a possibilidade de fazer descrições detalhadas de elementos manuais e não manuais, posicioná-los em uma linha de tempo, ter como fazer uma busca de termos e a exibição e sincronização do vídeo e áudio com a transcrição.

Apesar de se utilizar de glosas da língua oral para serem rótulos dos sinais em outra língua, não se escreve ou transcreve diretamente o sinal. Por esta razão, talvez não seja o ideal para pesquisas em interpretação interlíngue, no entanto ainda é o mais utilizado e mais adequado no momento.

Transcrever é assim um processo seletivo que reflete as concepções e os objetivos teóricos do investigador (OCHS, 1979). Por isso, não posso me furtar de comentar sobre certo incômodo em ainda não estar plenamente satisfeita com a ferramenta de transcrição que utiliza glosas e descrições provindas de uma língua oral para representar outra língua, de sinais socialmente ágrafa, pois vejo isso como problemático para um estudo sobre a interpretação interlíngue. Tenho que admitir, contudo, que não possuímos, atualmente, outras ferramentas melhores.

\section{Novas formas de atuação e a necessidade de consenso}

Atualmente, falarmos apenas de tradução e interpretação não é suficiente para abrangermos todas as formas possíveis de relação na transformação de uma mensagem em uma língua para outra. Não apenas falamos, vocalmente, e escrevemos. As línguas de sinais estão sendo reconhecidas, a tecnologia amplia as possibilidades de nos relacionarmos no tempo e no espaço. Diante desta realidade, temos que repensar nomenclaturas que foram estabelecidas em épocas anteriores ao uso massivo de tecnologias de informação e utilizá-los com cautela, ponderando se ainda são válidos. 
Concluindo, penso que uma revisão mais detalhada deveria ser feita ao escolhermos os termos que vão ser referências para nossos textos e com os quais a divulgação científica é feita. Algumas vezes a pressa em nomearmos determinada atividade pode levar a grandes problemas. Este tipo de problema ocorre, por exemplo, quando nos referimos à degravação e que é, em suma, a própria transcrição de um trecho de fala, armazenado por meio eletrônico.

Convém reafirmar que este trabalho, tanto para as línguas orais quanto para as línguas de sinais, envolvidas em um ato de interpretação interlíngue, não tem caráter definitivo, mas sim propositivo de uma discussão mais ampla entre os profissionais e pesquisadores dos Estudos da Tradução para que, minimamente, cheguemos a um consenso quando a questão for terminologia sobre a tipologia da interpretação.

\section{Notas}

1. No original: Interpreting is a form of Translation in which a first and final rendition in another language is produced on the basis of a one-time presentation of an utterance in a source language (POCHḦ̈CKER, 2004, p. 11). Tradução livre de Mylene Queiroz (QUEIROZ, 2011, p.32).

2. No original: interpretation or interpreting for a non-written re-expression of a non-written source text (GILE, 2004, p.11). Tradução livre de Maria Cristina Pires Pereira.

3. Third International Symposium on Sign Language Translation and Avatar Technology. DePaul University, in Chicago, Illinois, USA, on October 18-19, 2013. Disponível em: http://sltat.cs.depaul.edu/ 
4. Recentemente já é possível presenciar cenas correlatas em língua de sinais, quando um ILS ouvinte interpreta, e um intérprete surdo "copia” a sinalização, acrescentando elementos principalmente prosódicos.

5. Teoricamente, toda a língua de sinais teria uma versão tátil. Pessoas que nasceram ou ficaram surdas, desenvolveram a língua de sinais de sua comunidade e, após, ficam cegas, têm a possibilidade de utilizarem-se da língua de sinais tátil, expressa por movimentos e captada pelo tato.

6. No original: [...] the translation done in everyday circumstances by bilinguals who have had no special training for it (HARRIS, 1977). Tradução livre de Maria Cristina Pires Pereira.

7. No original: [...] what we do is train them to translate in accordance with certain norms. (LJUDSKANOV, 1972 HARRIS, 2008, p.12). Tradução livre de Maria Cristina Pires Pereira.

8. No original: [...] el término más adecuado para este fenómeno sería interpretación natural (HARRIS, 2003 apud FUENTE, 2007).

9. Em alguns casos a definição é estendida aos adolescentes, também, como child and adolescent language brokering. Para maiores informações, recomendo a consulta em Manchester Metropolitan University. Education and Social Research Institute. Research Projects. Children and Adolescents as Language Brokers. Bibliography. Acessivel online em: <http://www.esri.mmu.ac.uk/resprojects/ brokering/biblio.php $>$.

10. No original: [...] la pluralité de ces systèmes et les fonctions particulières pour lesquelles ils ont été créés peuvent compliquer la diffusion et l'accessibilité des recherches de chacun (MILLER, 1994 apud BERGERON, 2006, p. 6). Tradução livre de Maria Cristina Pires Pereira.

11. Disponível em: http://www.slls.eu/startguide/startguide.html\#Anchor-Transcription-35882, acessado em: 20 set. 2013.

12. Informações mais técnicas sobre transcrição de língua de sinais podem ser adquiridas nos anais dos workshops on the Representation and Processing of Sign 
Languages promovidos nos eventos periódicos de Language Resources and Evaluation Conference (LREC), disponíveis em: http://www.lrec-conf.org/.

13. No original: Researchers searching for a transcription model in the literature have found instead a bewildering variety of mutually incompatible systems (DRESSLER; KREUZ, 2000, p. 26). Tradução livre de Maria Cristina Pires Pereira.

14. ELAN (EUDICO Linguistic Annotator) é uma ferramenta de notação multimídia de aúdio e vídeo desenvolvida pelo Instituto de Psicolinguística Max Planck, Nijmegen, Holanda. Portal: http://tla.mpi.nl/tools/tla-tools/elan.

\section{Referências}

ALBRES, Neiva Aquino. Tradução e interpretação em Língua de Sinais como objeto de estudo: produção acadêmica brasileira: 1980 a 2006. In: 2o Encontro dos profissionais tradutores intérpretes de língua brasileira de sinais de Mato Grosso do Sul - 2o EPILMS, 2006, Campo Grande. ANAIS do 2o EPILMS. Campo Grande - MS: APILMS, 2006. v. 2.

ANTONINI, Rachele The study of child language brokering: Past, current and emerging research. MediAzioni 10, 2010.

BARROS, Mariângela Estelita. ELiS - Escrita das Línguas de Sinais: proposta teórica e verificação prática. Tese (Doutorado em Linguística), Centro de Comunicação e Expressão, Programa de Pós-Graduação em Linguística, Universidade Federal de Santa Catarina, 2008.

BERGERON, Louis-Félix. Typologie de Systèmes Écrits Pour les Langues Signées. RELQ/QSJL. Vol I, No. 2, Printemps/Spring 2006. 
BICOM. Promoting Bilingual \& Intercultural Competencies in Public Health. Ad hoc-interpreting in hospitals. Disponível em: < http://www.bicom-eu.net/booklet3.html > . Acesso em 03/06/2013.

BIDAR-SIELAFF, Shiva et al. Sight Translation and Written Translation: Guidelines for Healthcare Interpreters. National Council on Interpreting in Health Care Working Papers Series. 2009.

BOT, Hanneke. Dialogue interpreting as a specific case of reported speech. Interpreting, 7:2, p. 237-261, 2005.

BRAUN, Sabine. Multimedia communication technologies and their impact on interpreting. Audiovisual Translation Scenarios: Conference Proceedings, MuTra 2006.

CARDOZO, Maurício; HEIDERMANN, Werner; WEININGER, Markus (Ed.). A Escola Tradutológica de Leipzig. Frankfurt am Main: Peter Lang, 2009

DRESSLER, Richard A.; KREUZ, Roger J. Transcribing Oral Discourse: A Survey and a Model System. Discourse Processes, 29(1), p.25-36, 2000.

ESQUIVEL, Adriana. Language Brokering a Dynamic Phenomenon: A Qualitative Study Examining the Experiences of Latina/o Language Brokers. Scripps Senior Theses. Paper 52. Disponível em: < http://scholarship.claremont.edu/scripps_theses/52>. Acesso em 07 nov. 2012.

FLORES, Glenn et al. Errors in Medical Interpretation and Their Potential Clinical Consequences in Pediatric Encounters. PEDIATRICS Vol. 111 No. 1 January 1, p. $6-14,2003$.

. The Impact of Medical Interpreter Services on the Quality of Health Care: A Systematic Review. Medical Care Research and Review. vol. 62 no. 3 255-299, 2005.

FRYDRYCH, Laura Amaral Kümmel. Transcrição da Interpretação para a Libras: Uma Abordagem Enunciativa. Trabalho de conclusão de curso (Graduação em Letras). Departamento de Letras Clássicas e Vernáculas. Instituto de Letras. Universidade federal do Rio Grande do Sul. 2010. 
FUENTE, Esther Álvarez de la. Análisis Lingüístico de la Traducción Natural: Datos de Producción de dos Niños Gemelos Bilingües Inglés/Español. Facultad De Filosofía y Letras Departamento de Filología Inglesa. Doctorado en Traducción e Interpretación. Universidad de Valladolid, 2007.

FURTADO, Marco Mendes; ALMEIDA, Paula Ramalho; PASCOAL, Sara Cerqueira. Formar Intérpretes à Distância: $O$ ensino da interpretação remota e de teleconferência no ISCAP. Polissema: Revista de Letras do Instituto Superior de Contabilidade e Administração do Porto, N.9, p. 170-197, 2009.

GILE, Daniel. Translation Research versus Interpreting Research: Kinship, Differences and Prospects for Partnership. In: SCHÄFFNER, Christina (ed.). Translation Research and Interpreting Research: Traditions, Gaps and Synergies. Clevedon: Multilingual Matters Ltd, 2004. p. 10-43

GORSZCZYNSKA, Paula. The Potential of Sight Translation to Optimize Written Translation. In: AZADIBOUGAR, Omid (ed.). Translation Effects. Selected Papers of the CETRA Research Seminar in Translation Studies 2009. Disponível em: < http://www.kuleuven.be/cetra/papers/papers.html >. Acesso em: 25 out. 2013. Publicado em 2010.

GRBIĆ, Nadja; PÖLLABAUER, Sonja. Community Interpreting: signed or spoken? Types, modes, and methods. In: HERTOG, Erik; VEER, Bart van der (eds).Taking Stock: Research and Methodology in Community Interpreting. Linguistica Antverpiensia, New Series - Themes in Translation Studies (LANS TTS), p. 247-261, 2006.

HALL, Nigel; GUÉRY, Frédérique. Child Language Brokering: Some considerations. MediAzioni 10, 2010.

HARRIS, Brian. The importance of natural translation. (Revised version of a paper presented at the AILA World Congress, Stuttgart, August 1975). Working Papers in Bilingualism 12.96-114. Reprinted as Working Papers in Translatology 2, Ottawa, School of Translators and Interpreters, University of Ottawa. 1977.

; SHERWOOD, Bianca. Translating as an Innate Skill. Paper to the NATO Symposium on Language Interpretation and Communication, at the Giorgio Cini Foundation, Venice, 1977. Published in the proceedings, 1978. 
. An Annotated Chronological Bibliography of a Century of Natural Translation Studies: 1908-2008. Disponível em: <www3.uva.es/uvalal/Enlaces/B_ Harris-Natural_Translation.pdf > . Acesso em 20 mai 2011.

IVARS, Amparo Jiménez. La Traducción a la Vista. Un Análisis Descriptivo. Tese (Doutorado em Tradução e Comunicação). Facultat de Ciències Humanes i Socials. Universitat Jaume I, 1999.

JACOBS, Elizabeth A. et al. Impact of Interpreter Services on Delivery of Health Care to Limited-English-proficient Patients. Journal of General Internal Medicine, Volume 16, Issue 7, pages 468-474, July 2001.

KARLINER, Leah S. et al. Do Professional Interpreters Improve Clinical Care for Patients with Limited English Proficiency? A Systematic Review of the Literature. Health Services Research, Volume 42, Issue 2, pages 727-754, April 2007.

LESSA-DE-OLIVEIRA, Adriana Stella Cardoso. Libras escrita: o desafio de representar uma língua tridimensional por um sistema de escrita linear. ReVEL, v. 10, n. 19, 2012.

LUCIANO, Anita Holm Thomsen. A Interpretação Simultânea sob a ótica da Linguística Aplicada. Dissertação (Mestrado em Linguística Aplicada). Universidade Estadual de Campinas, Instituto de Estudos da Linguagem, 2005.

MACHADO, Emilia; FAMULARO, Rosana. Programa de Formación de Formadores de Intérpretes de Sordos Organizado por la FMS y la Unesco (Informe). Montevideo, Uruguay, noviembre 2001. Disponível em: < http://www.aati.org. ar/socios/LSA/programa_de_formacion.htm >. Acesso em 10 mar. 2010.

MEYER, Bernd. Ad hoc interpreting for partially language-proficient patients: participation in multilingual constellations. In: BARALDI, Claudio; GAVIOLI, Laura (Ed.). Coordinating Participation in Dialogue Interpreting. Jonh Benjamins Publishing Company, p. 99-113, 2012.

MIKKELSON, H. The Professionalization of Community Interpreting. Monterey Institute of International Studies. 2004. Disponível em: < http://www.acebo. com/papers/profslzn.htm > . Acesso em: 30 set. 2013. 
MORALES, Alejandro; HANSON, William E. Language Brokering: An Integrative Review of the Literature. Hispanic Journal of Behavioral Sciences, Vol. 27 No. 4, p. 471-503, November 2005.

NAJIT - National Association of Judiciary Interpreters \& Translators. Modes of Interpreting: Simultaneous, Consecutive, \& Sight Translation. Position Papers, May 15, 2006. Seattle: NAJIT, 2006.

NÁPOLES, Anna M. et al. Clinician Ratings of Interpreter Mediated Visits in Underserved Primary Care Settings with Ad hoc, In-person Professional, and Video Conferencing Modes. J Health Care Poor Underserved. 21(1): 301-317, 2010.

NICODEMUS, Brenda; EMMOREY, Karen. Direction asymmetries in spoken and signed language interpreting. Bilingualism: Language and Cognition, Volume 16, Issue 03, p. 624- 636, July 2013.

OCHS, Elinor. Transcription as Theory. 1979.

PEREIRA, Maria Cristina Pires; FRONZA, Cátia de Azevedo. Sistema Signwriting como uma Possibilidade na Alfabetização de Pessoas Surdas. In: (anais do VII) Encontro do Círculo Lingüístico do Sul (CELSUL). Pelotas: UCPEL e UFPEL. 2006.

. Interpretação interlíngüe: as especificidades da interpretação de língua de sinais. Cadernos de Tradução XXI, Vol. 1, p. 135-156. Florianópolis: UFSC, PGET: 2008.

PÖCHHACKER, Franz. Introducing Interpreting Studies. London: Routledge, 2004.

QUADROS, Ronice Müller de. As categorias vazias pronominais: uma análise alternativa com base na Libras e reflexos no processo de aquisição. Dissertação (Mestrado em Linguística e Letras), Pontifícia Universidade Católica do Rio Grande do Sul, 1995.

1997.

. Educação de Surdos: a aquisição da linguagem. Porto Alegre: Artmed, 
QUEIROZ, Mylene. Interpretação Médica no Brasil. Dissertação (Mestrado em Estudos da Tradução). Pós-Graduacao em Estudos da Tradução, Centro de Comunicação e Expressão, Universidade Federal de Santa Catarina, 2011.

RODRIGUES, Carlos Henrique. Situações de Incompreensão Vivenciadas por Professor Ouvinte e Alunos Surdos na Sala de Aula: Processos Interpretativos e Oportunidades de Aprendizagem. Dissertação (Mestrado em Educação), Faculdade de Educação, Universidade Federal de Minas Gerais, 2008.

. Da interpretação comunitária à interpretação de conferência: desafios para formação de intérpretes de língua de sinais. In: Anais do II Congresso Brasileiro de Pesquisa em Tradução e Interpretação de Língua de Sinais Brasilei$\mathrm{ra}$, 2010, Florianópolis. Florianópolis: UFSC, 2010. p.01-07. Disponível em: $<$ http://www.congressotils.com.br/anais2010/Carlos\%20Henrique\%20Rodrigues.pdf $>$. Acesso em: 20 fev. 2012.

. A interpretação para a Língua de Sinais Brasileira: efeitos de modalidade e processos inferenciais. Tese (Doutorado em Linguística Aplicada), Universidade Federal de Minas Gerais, 2013.

RUSSO, M. Community Interpreter, Liaison interpreter, ad hoc interpreter, Intercultural Mediator. What kind of curriculum for such multifaceted profession? In: Professionalization of interpreting in the community. International Conference Critical Link 4. Stockholm, Sweden, p. 1-9, 2004.

SAMPAIO, Glória Regina Loreto. Mastering Sight Translation Skills. Tradução e Comunicação, v. 16, p. 63-69, 2007.

SCHJOLDAGER, Anne. Review article: Silvana E. Carr, Roda Roberts, Aideen Dufour, and Dini Steyn (Ed.): The Critical Link: Interpreters in the Community. Papers from the First International Conference on Interpreting in Legal, Health, and Social Service Settings (Geneva Park, Canada, June 1-4, 1995). Amsterdam/ Philadelphia: John Benjamins, 1997.

STUMPF, Marianne Rossi. Aprendizagem de Escrita de Língua de Sinais pelo sistema SignWriting: Linguas de Sinais no papel e no computador. Porto Alegre: UFRGS, CINTED, PGIE, 2005. 
TRICKETT, Edison J., SORANI, Sandra; BIRMAN, Dina. Towards an ecology of the culture broker role: Past work and future directions, mediAzioni 10, 2010.

WADENSJÖ, Cecilia. Dialogue Interpreting and the Distribution of Responsibility. Hermes, Journal of Linguistics no. 14, p. 111-131, 1995.

. Interpreting as Interaction. London/New York: Longman. 1998.

. Dialogue interpreting: A monologising practice in a dialogically organised world.

Dialogue interpreting: A monologising practice in a dialogically organised world. Target 16:1, p.105-124, 2004.

Recebido em: 30/06/2015

Aceito em: 30/09/2015 